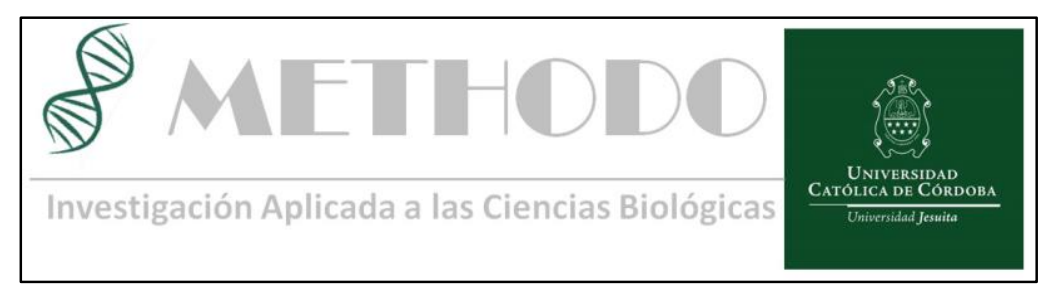

EDITORIAL Methodo 2018;3(2):27-28

DOI: $10.22529 / \mathrm{me} .2018 .3(2) 01$

Solicitado 10 Abr 2018 Recibido 18 May 2018 | Aceptado 30 May 2018|

Publicado 30 Jun 2018

\title{
La biotecnología y su vínculo con la educación universitaria
}

\section{Biotechnology and its link to university education}

En los últimos años, la ciencia ha cumplido un rol fundamental en el desarrollo de las poblaciones humanas mediante el análisis y comprensión de los procesos naturales. El crecimiento en conocimientos científicos-tecnológicos ha transformado las condiciones de vida, permitiendo en muchos casos, un avance económico y cultural, sobre todo en aquellos países en los cuales la biotecnología forma parte de sus investigaciones, permitiendo, por ejemplo, un mejor posicionamiento económico mundial . ${ }^{1}$ Algunos ejemplos de conocimiento e investigación que generaron cambios culturales en la humanidad, son los adelantos en nano ciencia, nanotecnología y bioinformática.

La biotecnología surge, de y en las ciencias, convirtiéndose en un campo de conocimiento interdisciplinario y en uno de los motores de transformación social, que necesariamente debe incluirse en la educación científica del presente y futuro estudiante. Los avances que se prevén en el área de la biotecnología en los próximos años requerirán de un entrenamiento específico en los estudiantes universitarios actuales, sin embargo, a pesar de los grandes cambios culturales, las Universidades en muchos casos, se resisten a ello, en un intento de conservar sus tradiciones más instaladas. ${ }^{2}$

En este contexto, los alumnos juegan un rol importante como agentes de cambio, por un lado, con sus nuevos perfiles y forma de percibir la realidad y, por otro lado, con el manejo de la tecnología y las comunicaciones, exigiendo a los docentes a cambiar la forma de enseñar. La Universidad debe hacer frente a los desafíos que presenta la sociedad, actuando no solo como una institución académica sino como agente de transformación que permita el desarrollo, la innovación, el progreso y el bienestar de la comunidad.

En conclusión, la enseñanza y el aprendizaje en biotecnología es esencial para los países en vía de desarrollo ya que permitirá preparar a las nuevas generaciones en la adquisición de habilidades y competencias científicas o competencias laborales.

Revista Methodo: Investigación Aplicada a las Ciencias Biológicas. Facultad de Medicina. Universidad Católica de Córdoba. Jacinto Ríos 571 Bo Gral. Paz. X5004FXS. Córdoba. Argentina. Tel.: (54) 3514517299

/ Correo: methodo@ucc.edu.ar / Web: methodo.ucc.edu.ar |EDITORIAL Methodo 2018;3(2):27-28 
A largo plazo, esto permitirá formar jóvenes profesionales con conocimientos profundos que sirvan para la toma de decisiones con responsabilidad, en el desarrollo de una Nación que progrese a través de la ciencia y tecnología, como actualmente lo sostienen los países más avanzados y de esta manera lograr una competencia más equitativa con ellos.

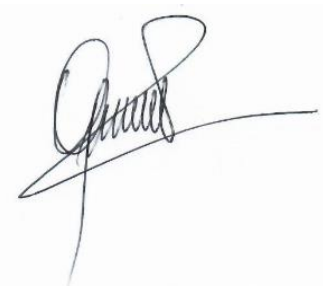

Dra. Georgina Díaz Napal

Secretaria de investigación, posgrado y vinculación tecnológica

Facultad de Ciencias Agropecuarias

Universidad Católica de Córdoba

1. Roa-Acosta R., García-Sandoval Y., Chavarro-Amaya C. Formación de profesores de Biología a través de la Biotecnología, Educación y educadores,2008, 11,69-88.

2. Lorenzo MG.Los sistemas externos de representación en la construcción del conocimiento científico en el aula universitaria. Enseñanza de las ciencias,2017;36(2) 1703-1709.

Revista Methodo: Investigación Aplicada a las Ciencias Biológicas. Facultad de Medicina. Universidad Católica de Córdoba. Jacinto Ríos 571 Bo Gral. Paz. X5004FXS. Córdoba. Argentina. Tel.: (54) 351 4517299 / Correo: methodo@ucc.edu.ar / Web: methodo.ucc.edu.ar | EDITORIAL Methodo 